\title{
EVOLUCIÓN HISTÓRICA DE LA CERVECERÍA CUAUHTÉMOC: UN GRUPO ECONÓMICO DE CAPITAL NACIONAL
}

\author{
Beatriz Pérez Sánchez*, Andres Guzmán Sala**, Armando Mayo Castro***
}

\begin{abstract}
Pérez-Sánchez B., Guzmán-Sala A., Mayo-Castro A. Evolución histórica de la cervecería cuauhtèmoc: un grupo económico de capital nacional. Hitos de Ciencias Económico Administrativas 2012;18 (52):119-136.
\end{abstract}

\section{RESUMEN}

Objetivo: Conocer la evolución histórica de una gran empresa de capital nacional y abordar las estrategias que ha puesto en práctica hasta constituirse en un gran corporativo o grupo económico. Se parte del enfoque del devenir histórico en el que prevalece el análisis de los orígenes y evolución de la empresa. Por ende predomina la crónica y las descripciones, reúne acontecimientos de la vida nacional y local de Monterrey, con la guía de un orden cronológico, logrando establecer planteamientos analíticos.

Material y Método: Los métodos que se utilizaron fueron el método histórico-crítico, el método analítico con un enfoque dinámico y el método comparativo. Se utilizaron los enfoques: 1) regional, 2) de origen histórico y 3 ) de estrategias corporativas y organizaciones. EI enfoque regional considera que el origen regional es un factor importante en las prácticas económicas y políticas de los empresarios mexicanos. El segundo da mayor peso al origen histórico y a las condiciones de surgimiento para establecer la configuración definitiva, las prácticas económicas y políticas predominantes y los patrones de desarrollo de los grupos. El tercer enfoque atiende la cambiante estructura organizativa de las grandes corporaciones modernas y su tendencia a adoptar estructuras de administración y morfologías corporativas más complejas. Se establece el método comparativo para tener en cuenta aquellas situaciones en que las características comunes de las empresas se combinan con circunstancias históricas que preceden a la formación de grandes corporativos de Monterrey.

Resultados: No se pretendió hacer un análisis histórico profundo, sino identificar y reconocer los eventos históricos y particularidades del comportamiento empresarial en Monterrey a fin de rescatar una presencia socioeconómica activa, que llevara a

\begin{abstract}
Pérez-Sánchez B., Guzmán-Sala A., Mayo-Castro A. Historical evolution of Cerveceria Cuauhtemoc: an economic group of national capital. Hitos de Ciencias Económico Administrativas 2012;18 (52):119-136.
\end{abstract}

\section{ABSTRACT}

Objective: To know the historical evolution of a great company of national capital and to know more about the strategies that it has put into practice until becoming a great corporation or economic group. This paper starts on the approach of the historic becoming where the analysis of the origins and evolution of the company prevails. Thus, chronic and descriptions predominate in the paper, also local events of Monterrey are gathered as well as national life events, with the guidance of a chronological order, managing to establish analytical approaches.

Material and Method: The historical - critical method, the analytical method with a dynamic focus, and the comparative method were used. The approaches used were: 1) regional, 2) of historical origin and 3 ) of corporate strategies and organizations. The regional approach considers that the regional origin is an important factor in the economic and political practices of the Mexican businessmen. The second approach gives major weight to the historical origin and to the conditions of emergence to establish the definitive configuration of the company, the predominant economic and political practices, and the patterns for group development. The third approach focuses its attention on the changeable organizational structure of the big modern corporations and their trend to adopt more complex structures of administration and corporate morphologies. The comparative method is established to bear in mind those situations in which the common characteristics of the companies are combined with historical circumstances that precede the formation of big corporations of Monterrey.

Results: There was no intention to make a deep historical analysis but to identify and recognize the historical events and particularities of the managerial

* Doctor en Economía. Profesora-Investigadora. División Académica de Ciencias Económico Administrativas. Universidad Juárez Autónoma de Tabasco (UJAT).

** Doctor en Ciencias Económicas con especialidad en Economía Turística y Comercio Internacional. Profesor-Investigador. División Académica de Ciencias Económico Administrativas. Universidad Juárez Autónoma de Tabasco (UJAT).

*** Doctor en Finanzas Públicas. Profesor-Investigador. División Académica de Ciencias Económico Administrativas. Universidad Juárez Autónoma de Tabasco (UJAT).

Fecha de recibido: 25 de julio de 2012 Fecha de aceptación: 1 de septiembre de 2012. 
considerar el surgimiento de un gran corporativo o grupo económico que ha transitado a la lógica nacional. Se abordó a Fábrica de Hielo y Cerveza Cuauhtémoc desde su constitución como empresa en 1890 hasta 1982. Al periodo comprendido entre 1890 y 1910 se le puede considerar como la etapa de surgimiento de las grandes empresas manufactureras en México, período que corresponde al Porfiriato. El patrón de inversiones que predominó dio como resultado una gran concentración del capital en los sectores de ferrocarriles, minería y banca, aunque también en algunas empresas del sector industrial como Fábrica de Hielo y Cerveza Cuauhtémoc (hoy Fomento Económico Mexicano, S.A.). En Monterrey surgieron en esta época grandes empresas que todavía subsisten y son la base de varios grupos o corporativos industriales actuales.

Conclusiones: El nacimiento industrial de Monterrey es el resultado lógico de un proceso de acumulación de capital dentro del ámbito comercial y de la necesidad de esos capitales de hallar nuevos campos de aplicación que posteriormente invirtieron en la esfera industrial. Los factores a los que podemos atribuir el desarrollo industrial de Monterrey corresponden al apoyo permanente del Estado y a factores geográficos favorecedores y a coyunturas históricas de México. Una segunda etapa de periodización de las grandes empresas se localiza en los años que van de 1930 a 1950 y se caracteriza por la instalación de empresas dedicadas a sustituir importaciones y la producción orientada hacia un mercado nacional y donde el Estado orientó el proceso de desarrollo. En Monterrey, Cervecería Cuauhtémoc, surge en el treinta como grupo empresarial integrado. En una tercera etapa que va de 1951 a 1970 se da propiamente el surgimiento del grupo económico de la Cervecería Cuauhtémoc cuando sus inversiones se dirigen hacia la integración tanto horizontal como vertical y la diversificación en la producción de las empresas, así como la suscripción de sus principales empresas en la Bolsa de Valores y la formación de un holding.

Palabras clave: Corporativos. Grandes empresas. Grupo Monterrey. Fracción Monterrey. Holding company. lindustria cervecera. Industria del vidrio. Integración vertical. Historia económica. behavior in Monterrey in order to rescue a socioeconomic active presence leading to consider the emergence of the great company or economic group that has transcended to the national logic. The company was analyzed since it was a beer and ice company (Fábrica de Hielo y Cerveza Cuauhtémoc) (1890) until it was constituted as a company in 1982. It is possible to consider the period between 1890 and 1910 as the stage of emergence of the biggest manufacturing companies in Mexico, and this period corresponds to the Porfiriato. The pattern of investments that prevailed resulted in a great concentration of capital in the sectors of railroads, mining industry and banking, and also in some companies of the industrial sector like Fábrica de Hielo y Cerveza Cuauhtémoc (today Fomento Económico Mexicano, S.A.). Big companies emerged in Monterrey in this epoch, and they still subsist there being the basis of several existing industrial and corporate groups.

Conclusions: The industrial birth of Monterrey is the logical result of a process of capital accumulation within the commercial ambit and the need of those capitals to find new fields of application that later invested in the industrial sphere. The factors to which we can attribute Monterrey's industrial development correspond to the permanent support of the State and to geographical favoring factors as well as to historical conjunctures of Mexico. The second stage of the big companies is considered from 1930 to 1950 and it is characterized by the installation of companies devoted to replace imports and the production oriented towards a domestic market where the State led the process of development. In Monterrey, the Cervecería Cuauhtémoc (a brewery manufacturer), arises in 1930 as a managerial integrated group. In a third stage that goes from 1951 to 1970 is when the real emergence of the economic group of Cervecería Cuauhtémoc is given, and it is also when its investments are addressed to both, the horizontal and vertical integration and the diversification in the production of the companies, as well as the subscription of its principal companies in the Stock exchange market and the formation of a holding company.

Key words: Corporate. Big companies. Group Monterrey. Fraction Monterrey. Holding company. Beer industry. Glass industry. Vertical integration. Economic history.

DIRECCIÓN PARA RECIBIR CORRESPONDENCIA: Correo electrónico: beatrizperez10@hotmail.com

En México, por una parte, la historia empresarial actual intenta situar sus objetos de estudio en el contexto de la historia económica, se mueve de preferencia en el largo plazo y privilegia el enfoque regional (Romero lbarra, 2003). Por otra, es necesario recordar que el desarrollo capitalista de México, ha sido un capitalismo tardío; es decir, dependiente, y se asocia un oligopolio precoz que al desarrollarse a partir de una base de acumulación débil y poco diversificada pero en un contexto internacional capitalista constituido, agudiza las contradicciones propias de todo desarrollo capitalista, sin dejar de reproducir las asociadas al retraso histórico (Cordera \& Ruíz A., 1980). Por ello, para establecer los orígenes de las grandes empresas o corporativos, se debe conocer la experiencia histórica, tratar de vincular la reflexión acerca de la relación entre nuevas maneras de organización económica y procesos generales de modernización económica; es decir, se trata de analizar la relación entre la creación de empresas modernas y el despegue de una economía de tipo capitalista. 
EI Porfiriato: antecedentes de la industria cervecera en México.

El capital y el capitalismo como sistema productivo fueron los que tendieron a imponer su hegemonía a la política económica que caracterizó al Porfiriato. Entre 1870 y 1910 se multiplicaron las grandes empresas modernas, distintos procesos operaron al mismo tiempo: 1) la ampliación de los mercados regionales y el creciente proceso de vinculación entre los mismos; 2) las nuevas corrientes de inversiones extranjeras desde el decenio de 1880; 3 ) el desarrollo de mercados de capitales locales; y 4) la creación de nuevos marcos institucionales para las actividades económicas. Todos estos procesos contribuyeron al nuevo panorama que permitiría una aceleración del desarrollo capitalista en el país.

En este contexto, la industria cervecera mexicana se dio aparejada con el nacimiento de la industria moderna porfiriana (1880-1910); fue una época en donde comenzaron a establecerse empresas de gran tamaño que requerían de capitales cuantiosos y que por lo general utilizaron la forma de sociedad anónima para organizarse legalmente. En este período se dio el nacimiento de fábricas que comenzaron a producir bienes de consumo, -cerveza cigarros, jabón-y bienes intermedios-acero, cemento y petróleo-. La época en que se formaron empresas ferrocarrileras con enormes capitales y en los que aparecieron las primeras instituciones bancarias para dar una mayor agilidad a una economía que comenzaba a industrializarse. Los empresarios tuvieron que hacer uso de recursos propios, por lo general fruto de actividades comerciales y de sus familiares para el establecimiento de las nuevas industrias.

A finales del siglo XIX, la mayoría de la cerveza consumida en el país era importada de Estados Unidos, Alemania e Inglaterra; además era una bebida de lujo que era adquirida por las comunidades de extranjeros asentadas en el país. La cerveza ya se producía y consumía en México, se producía de forma artesanal y no se comercializaba a gran escala. Otras bebidas alcohólicas como el pulque y el mezcal, eran mucho más importantes en las preferencias de los consumidores. En 1877, se producía cerveza en diversos Estados del país como puede observarse en la Tabla I; sin embargo, fue a finales del siglo XIX que la industria cervecera «moderna» surgió en México junto con el establecimiento de la mayoría de las grandes fábricas con tecnología importada.

La fundación de la Fábrica de Cerveza y Hielo Cuauhtémoc, se remonta al 16 de diciembre de 1890, cuando Isaac Garza y J.M. Schneider pidieron al Estado una concesión para la creación de una fábrica de vidrio y de cerveza de exportación. El 20 de diciembre obtuvieron exención de impuestos por 7 años. La Fábrica de Cerveza y Hielo Cuauhtémoc
TABLA I. PRODUCCIÓN DE CERVEZA POR ESTADO 1877

\begin{tabular}{lc}
\hline Estados & Producción en barriles \\
\hline Aguascalientes & 3,995 \\
Colima & 1,236 \\
Distrito Federal & 46,890 \\
Estado de México & 1,126 \\
Guanajuato & 12,356 \\
Jalisco & 16,276 \\
Michoacán & 4,175 \\
Puebla & 7,390 \\
San Luís Potosí & 6,815 \\
Veracruz & 7,320 \\
Producción total & 109,333 \\
\hline
\end{tabular}

Fuente: Secretaría de Hacienda, Estadística de la República Mexicana por Emiliano Busto, 1880, Cuadro Sinóptico General de la Industria Agrícola de la República Mexicana, Cuadro 3, tomado de Gabriela Recio El nacimiento de la industria cervecera en México, 1880-1910, www.economia.unam.mx/amhe/memoria/gabrielarecio.

comenzó a operar a finales de 1891 y es el origen de Fomento Económico Mexicano S.A., FEMSA. La empresa inició con 70 obreros, 2 personas de administración y 100 mil pesos de capital. Con la fundación de la Cervecería Cuauhtémoc se marca el inicio de un cambio en la estructura de producción cervecera en México. Prueba de ello es que el valor de las importaciones de cerveza cayó en un $70 \%$ en el periodo comprendido entre los años fiscales de 18881889 y 1910-1911 (Rosenzweig, 1965), mientras que la producción nacional se incrementó alrededor de un $147 \%$ en el periodo 1880-1899 (INEGI, 1900).

La primera marca que Cervecería Cuauhtémoc lanzó al mercado fue Carta Blanca y después Saturno, una marca que duró muy poco tiempo y luego desapareció. En botella transparente con tapón de corcho reforzado con alambre, se convirtió en la marca de vanguardia de la empresa y una de las de mayor venta en México. En 1892 la Fábrica de Cerveza realizó la primera de una larga lista de innovaciones, cambiando las barricadas utilizadas para guardar botellas por cajas de maderas que facilitaban su transportación. En 1893 salió al mercado la primera cerveza de barril con el nombre de Cuauhtémoc, su éxito fue tan grande que la producción de cerveza de barril se convirtió en constante.

La mayoría de las grandes empresas cerveceras mexicanas fueron establecidas después de 1890 como puede observarse en la Tabla II. El consumo de cerveza era más alto en las grandes ciudades así como en aquellas localidades del norte de México cercanas a los Estados Unidos. Las grandes urbes 
TABLA II. PRINCIPALES FÁBRICAS DE CERVEZA EN MÉXICO. 1860-1900

\begin{tabular}{llc}
\hline Estados & \multicolumn{1}{c}{ Compañía } & $\begin{array}{c}\text { Año de } \\
\text { fundación }\end{array}$ \\
\hline Chihuahua & Cervecería de Chihuahua & 1896 \\
& Cervecería San Diego Cervecería & 1860 \\
Distrito Federal & Alsaciana * & 1881 \\
& Cervecería Central & 1899 \\
Jalisco & Cervecería la Estrella & 1900 \\
Estado de México & Compañía cervecera Toluca y México & 1875 \\
Nuevo León & Cervecería Cuauhtémoc & 1890 \\
Sinaloa & Cervecería del Pacífico & 1900 \\
Sonora & Cervecería Sonora & 1896 \\
Veracruz & Cervecería Moctezuma & 1894 \\
Yucatán & Cervecería Yucatán & 1900 \\
\hline
\end{tabular}

Fuente: Tomado de Gabriela Recio El nacimiento de la industria cervecera en México, 1880-1910, Cuadro No. 2 pág. 7 www.economia.unam.mx/amhe/memoria/gabrielarecio. *En 1895 se convierte en Sociedad Anónima y cambia su nombre a Compañía Cervecera La Cruz Blanca.

tenían más consumidores y abarcaban la mayoría de los asentamientos de extranjeros de aquella época. En el Norte de México con escasa población, el consumo de cerveza se explica dado a que no se elaboraba el pulque y el mezcal -la bebida local- era bastante fuerte; así la cerveza se presentó en esa región como un sucedáneo más suave.

En 1899 cinco empresas dominaban el mercado, la Compañía Cervecera de Chihuahua, S.A., la Compañía Cervecera de Toluca y México, S.A., la Cervecería Cuauhtémoc, S.A., Ia Cervecería Sonora, S.A., y la Cervecería Moctezuma, S.A., controlaban el $74.61 \%$ de la producción nacional (Secretaría de Fomento Colonización e Industria, 1900); sin embargo en 1899 existían 72 cervecerías en todo el país, este número se redujo a 29 , lo cual nos señala que ya para principios del siglo XX muchas de las pequeñas fábricas no habían tenido éxito y las grandes empresas iban conquistando nuevos mercados regionales. La Cervecería Cuauhtémoc comenzóa utilizarlapublicidad desde épocas tempranas para dar a conocer sus productos, así como para competir por mercados nacionales. Utilizó como publicidad el hecho de que su cerveza Carta Blanca había ganado el primer premio en la Exposición Mundial de Chicago, primer premio en la Exposición de París (1900), así como primer premio en la Exposición de St. Louis Missouri (1904) (Dávalos, 1930),como se puede observar en la Tabla III.

El 20 de octubre de 1899 se constituyó la Fábrica de Vidrios y Cristales de Monterrey, S.A., respaldada con un capital de 600 mil pesos, la planta fue instalada para manufacturar todo tipo de productos de vidrio y cristal entre los que debían sobresalir, al menos inicialmente, las botellas. Cervecería Cuauhtémoc, que utilizaba envases importados, iba a resultar su primer y principal comprador. Sin embargo, el sistema de fabricación utilizado seguía la tradición alemana del soplado individual, para lo que se hicieron traer obreros de aquel país, altos salarios, tensas relaciones de los trabajadores europeos con la patronal y un muy serio problema planteado por la calidad de las materias primas llevaron a fines de 1903 -menos de un año después de comenzar
TABLA III. PREMIOS Y RECONOCIMIENTOS DE LA CERVECERÍA CUAUHTÉMOC 1893-1908

\begin{tabular}{|c|c|c|}
\hline Año & Exposición & Premio \\
\hline 1893 & Exposición universal de Chicago & Primer premio \\
\hline 1900 & Exposición universal de París & Medalla de oro \\
\hline 1902 & Exposición de Durango & Única medalla de oro \\
\hline 1904 & Exposición de san Louis Missouri & Único gran premio \\
\hline 1905 & Exposición de Lieja, Bélgica & Único gran premio \\
\hline 1905 & $\begin{array}{l}\text { Academia imperial y real de cerveceros de } \\
\text { Baviera }\end{array}$ & Certificado honorífico \\
\hline 1906 & Exposición de Milán, Italia & $\begin{array}{l}\text { Único gran premio } \\
\text { Único gran premio, medalla }\end{array}$ \\
\hline 1907 & Exposición de alimentación e higiene, París & de oroy cruz de honor \\
\hline 1907 & Exposición universal de Amberes & Único gran premio \\
\hline 1908 & Exposición universal de Madrid, España & $\begin{array}{l}\text { Presidente del jurado } \\
\text { internacional de cervezas }\end{array}$ \\
\hline 1908 & $\begin{array}{l}\text { SM Alfonso XIII Rey de España, nombró a la } \\
\text { empresa proveedora oficial de la casa real, } \\
\text { por lo que le permitió el uso del escudo } \\
\text { español de armas en etiquetas y papelería }\end{array}$ & \\
\hline
\end{tabular}

Fuente: Revista El tiempo Ilustrado, 1910, tomado de www.issuu.com/isabelortega/docs/cebadaymalta. 
a operar- a que la empresa quebrara. No obstante, ese año continuaron las innovaciones: los corchos reforzados de las botellas fueron reemplazados por primera vez por la corcholata, facilitando las tareas de envasado y brindando comodidad al consumidor.

Apesar de los problemas tecnológicos que enfrentaba la Fábrica de Vidrios y Cristales, los empresarios siguieron buscando soluciones para poder fabricar en Monterrey botellas de buena calidad; sin embargo los empresarios de la Cervecería Chihuahua que compartían la misma preocupación andaban en busca de maquinarias que produjeran botellas de vidrio de forma automática; por tanto, a nivel internacional no fue sino hasta 1903 que la nueva tecnología fue patentada por el Sr. Owens en Estados Unidos. Este invento fue comercializado por la Toledo Glass Company quien a su vez estableció convenios con la Owens Bottle Machine Company y la Kent Machine Company para la fabricación de la maquinaria; estas compañías fueron responsables de establecer un sistema de licencias tanto a nivel nacional como internacional (Barragán \& Cerutti, 1993).

Los dueños de la Cervecería Chihuahua decidieron constituir en 1905 la Owens en México, S.A., amparaba una muy reciente tecnología, que remplazaba los procesos manuales en la elaboración de botellas. Su inventor había patentado en Ohio, entre 1903 y 1905 los componentes de una maquinaria que eliminaba los procesos de succión mediante un sistema de vacío. La comercialización del invento quedó a cargo de la Toledo Glass Co., fabricante de las máquinas automáticas.

Los empresarios de la Cervecería Chihuahua, también eran socios de la Fábrica de Vidrios y Cristales, por ello organizaron las tratativas (junio de 1905) entre Cervecería Cuauhtémoc y la Owens en México,S,A. Las negociaciones fueron prolongadas y tortuosas, incluso vivieron una ruptura de dos años. Sin embargo, en 1908 un incendio destruyó la Cervecería Chihuahua quitándola del mercado, así el 9 de diciembre de 1909 finalmente, Vidriera de Monterrey, S.A., quedó constituida. John Brittingham incorporó la patente Owens (valuada en 400 mil pesos), mientras que el equipo Garza/Sada/Muguerza aportaba los activos de la ya disuelta Fábrica de Vidrios y Cristales de Monterrey (cotizados, también, en 400 mil pesos). Con una inversión adicional de otros 400 mil, el capital ascendió a un millón doscientos mil pesos (unos 600 mil dólares de entonces), fraccionada en doce mil acciones.

El primer consejo directivo procuró balancear los intereses asociados (Cerutti, 2000). La empresa operaba con un horno y dos de las primeras máquinas automáticas formadoras de envase de vidrio en el mundo. Con la formación del grupo cervecero, pivote y núcleo central del surgimiento del Grupo Monterrey se abre el camino para la producción a gran escala en México de otros capitales regionales como Veracruz y
Yucatán. Al principio, su producción fue solamente de 60 mil barriles de cerveza y 8 mil toneladas de vidrio por año. No obstante, creció rápidamente, en 1903 producía 100 mil barriles por año y 365 toneladas de vidrio al día. En 1909 el valor real de la Cervecería alcanzó la cifra de $\$ 8$ millones. El personal efectivo estaba compuesto por 1500 obreros y empleados y la producción era de 300 mil barriles por año (Mauro, 1972).

\section{Época revolucionaria: paralización empresarial} La historiografía ortodoxa (Collado, 2004), concibió al porfiriato como un régimen autoritario, opresivo y extranjerizante, y contempló al movimiento armado que dio inicio en 1910 como una auténtica revolución social con contenido de clase, caracterizándola como popular, agraria y espontánea, por lo cual condujo a una violenta confrontación entre los campesinos y los terratenientes. De acuerdo con Basave (Basave Kunhardt, 2001), la violencia, inestabilidad política y destrucción física que prevaleció durante la Revolución frenó el proceso de inversión de los grupos empresariales y con escasas excepciones prácticamente se canceló toda nueva inversión entre 1910 y la primera mitad de los años veinte. La lucha armada influyó poderosamente en el deterioro de la economía en su conjunto, la producción en los sectores minero y agropecuario decreció en más de $40 \%$ y el sector industrial lo hizo en $25 \%$ (Hernández Laos, 1985).

No obstante, la revolución encontró a la burguesía regiomontana con el poder y solidez socioeconómica suficiente como para capear los problemas que desató la propia Revolución. El sustento industrial de este empresariado, le permitió mantener a mediano plazo condiciones suficientes para su reproducción capitalista, aún cuando el hecho de que muchos burgueses fuesen terratenientes afectados por la caída de Porfirio Díaz (Cerutti, 1983). En el momento de la Revolución, Monterrey era la cuarta ciudad del país y ocupaba idéntico puesto en lo que atañe a la tasa de crecimiento anual de población (3.7\%) en urbes con más de 25 mil habitantes en el periodo 1895-1910. El crecimiento poblacional de Monterrey se acompañó además por las migraciones desde estados vecinos y cercanos. La mayoría provenía de San Luís Potosí, Coahuila, Durango, Tamaulipas, Zacatecas, Guadalajara y Aguascalientes. En 1900, el 33\% de los habitantes de la ciudad eran originarios de otros estados (Labastida, 1986).

El estallido de la Revolución golpeó las áreas productivas bajo el dominio capitalista y precipitó la desintegración de un mercado en pleno proceso de definición como mercado nacional. Los factores que influyeron en esta desintegración tienen que ver con el uso militar de los ferrocarriles (ya que buena parte de las vías férreas fueron destruidas como parte de las acciones estratégicas de los diferentes ejércitos), la caída de la 
demanda de bienes y servicios, y la falta de materias primas estratégicas -como los combustibles- ante el desmantelamiento de las redes de circulación (Cerutti, Ortega, \& Palacios, 2000).

En 1914 las fuerzas de Pablo González tomaron la ciudad y la Fábrica de Cerveza y Hielo Cuauhtémoc fue incautada, aunque en noviembre de ese mismo año cesó la incautación ante las presiones diplomáticas inglesas, estadounidenses y alemanas que permitieron recuperar las instalaciones. Posteriormente, fueron asaltadas entre marzo y mediados de 1915 en varias ocasiones por grupos revolucionarios de distinta filiación. A pesar de que hacia 1916 cesaron los asedios directos, la planta no reinició su producción. En 1919 con un ambiente político y económico difícil, la Cervecería Cuauhtémoc reinició la producción parcial en su planta.

Entre 1910 y 1920 las importaciones de cervezas aumentaron como respuesta los problemas de distribución a las que se vieron envueltas las cervecerías mexicanas. Sin embargo, por una parte al finalizar la contienda armada, las importaciones volvieron a caer dramáticamente debido al inicio de la Prohibición en 1919 en los Estados Unidos y por otra que a comienzos de 1921 la Cervecería Cuauhtémoc reinició su producción total, después de siete años, cuando se da el funcionamiento de los ferrocarriles, el aprovisionamiento de combustibles y el acceso al consumo interior (Cerutti, 2000).

Las pérdidas soportadas en 1913, 1914 y 1915 ascendieron a más de 1600000 pesos (unos 800 mil dólares), el capital social quedó intacto según indicó una revaluación que se hizo de bienes raíces y máquinas. En 1916, las cuentas de la compañía expresaron una especie de «borrón y cuenta nueva» y se recomenzó con un capital de 5 millones de pesos (2 millones y medio de dólares), similar al que se tenía en 1909.

Cervecería puso en práctica diversas estrategias para afrontar tales dificultades: a) reorganizó el personal (obreros y empleados de oficina) para lograr mayor eficiencia y eliminar puestos que no fuesen indispensables; b) mejoróla administración, en especial los sistemas de contabilidad para poder conocer mensualmente el resultado de los negocios; c) solucionó parcialmente el problema del transporte mediante la compra de vagones de ferrocarril; d) perfeccionó el sistema de ventas, ajustándolo a las circunstancias del momento; e) la gerencia intensificó las labores de cobro a deudores de la época anterior; f) por último, se reestructuró una gran parte de las deudas al conseguir que la mayoría de los acreedores le dispensaran los intereses (Cerutti, 2003).

La escasez de materias primas habitualmente procedentes de Estados Unidos obligó en 1919 a la instalación de una planta elaboradora de gas carbónico destinado tanto a la elaboración de hielo como a la refrigeración de las bodegas. La planta de Fuerza Motriz y Refrigeración tuvo un costo superior a los 50 mil dólares (114 mil pesos) y significó un doble beneficio: además de proveer las necesidades de consumo en la empresa, se colocaba el excedente de gas en el mercado (con diferentes usos, entre otros para aguas gaseosas).

La empresa Vidriera Monterrey, S.A., enfrentó diversas dificultades para seguir operando, es hasta finales de 1915, que la vidriera comenzó a funcionar nuevamente en muy pequeña escala con una sola unidad productiva. Para 1918 la economía de México mostró síntomas de mejoría y por primera vez en su historia, Vidriera pagó a sus accionistas un dividendo de $6 \%$ sobre su capital social. El 30 de marzo de ese año, se constituyó la Sociedad de Ahorros e Inversiones para los Empleados y Operarios de la Cervecería Cuauhtémoc, S.A., con el propósito de fomentar el desarrollo integral de los trabajadores de la Cervecería y sus familiares. Los objetivos originales fueron proporcionar despensas para mejorar el nivel adquisitivo del salario, así como servicios médicos, caja de ahorro, descuentos, deportes, cursos y becas, entre otras prestaciones.

Los años veinte: expansión e integración vertical El periodo posrevolucionario de 1921 a 1930 fue de esfuerzos institucionales para convertir el país de minero, petrolero y agropecuario, en un país en proceso de industrialización. Es importante señalar de acuerdo con Basave (Basave Kunhardt, 2001), que durante los años veinte, el capital estadounidense por su parte había logrado controlar de nuevo importantes inversiones. Fue un periodo de instalación de filiales de grandes trasnacionales en territorio nacional (fenómeno que volvería a presentarse con posterioridad a la segunda guerra mundial).

La recuperación de mediados de los años veinte sugiere que algunos empresarios de Monterrey lograron consolidarse financieramente e iniciar una primera etapa de expansión, así como fundar nuevas empresas. La Cervecería Cuauhtémoc desarrolló productos complementarios de su proceso productivo. Inauguró a mediados de los veinte un ciclo de integración productiva, de reorganización operativa y de expansión en el plano de la distribución destinado a conquistar porciones sustanciales del mercado interno. Dicho proceso vivió un momento decisivo entre 1925 y la década de los cincuenta, cuando acompañó con agilidad las políticas que iba definiendo el nuevo Estado, compartió el reto de la industrialización sustitutiva y aprovechó las ventajas y facilidades que se ofrecían al empresariado fabril, convirtiendo a la empresa en una organización de referencia en el contexto mexicano. 
En 1920 la Cervecería Cuauhtémoc construyó una planta de fuerza motriz (alimentada con carbón) que para los años veinte era insuficiente; los primeros pasos en materia de diversificación productiva incluyeron la instalación dentro de la Cervecería de: a) una fábrica de gas carbónico (insumo utilizado para tornar más espesa la espuma y facilitar el servido de la cerveza de barril); b) el departamento de cajas de cartón corrugado (que en 1926 sustituyeron al embalaje en cajas de madera); c) el departamento de elaboración de tapones corona (que había suplantado al corcho desde 1903) y de envases metálicos; d) una fábrica de malta (en 1928). Algunos de estos departamentos pronto requirieron edificios propios e incluso posteriormente se independizaron de la Cervecería.

En 1927 la Fábrica de cajas de cartón comenzó a abastecer de manera simultánea la demanda de cajas de cartón de casas comerciales, oficinas e industrias. La planta resultó todo un éxito. Como sus artículos tuvieron excelente recepción fuera de Cervecería, estimuló la compra de maquinaria especial para manufacturar empaques con formas distintas y atender las necesidades de un mercado interno que brindaba señales de firme expansión.

La malta, insumo fundamental para elaborar la cerveza, se importaba de Estados Unidos desde el inicio de la producción, en 1892. Desde los comienzos del siglo $\mathrm{XX}$, en especial con la Primera Guerra, surgieron claros problemas de abastecimiento. En 1928 el alza inmoderada y repentina de los derechos de importación (en el caso de la malta pasó de 8 a 14 centavos por kilogramo), tornó imperativa la construcción de la planta: se situó en el edificio de la antigua fábrica de hielo, que fue remodelado. Se programó para que produjera por los menos $60 \%$ de la malta necesaria, es decir cerca de 3 millones de kilogramos anuales.

En 1928 las corcholatas que eran elaboradas con lámina de metal en una pequeña planta dentro de la misma cervecería resultaron insuficientes para las necesidades de su propio consumo y para atender el mercado local. Se adquirió entonces maquinaria para ampliar la producción pero la falta de espacio presentó un nuevo problema, dado su crecimiento, la fábrica ya no podía estar contenida dentro del edificio principal. Se construyó un nuevo edificio a un costado del productor de cajas de cartón.

En un proceso de expansión, se planteó que las actividades que no mantenían relación exclusiva con la elaboración de cerveza se manejaran como sociedades anónimas independientes y bajo nombres distintos. El objetivo era facilitar su desarrollo y ampliar las ventas. Así, en 1929 surgió Fábricas Monterrey S.A. de C.V., (FAMOSA) que se inició con la producción de corcholatas, amplió la gama hacia tapas para distintos tipos de botellas y frascos, creció y expandió su producción para incluir envases metálicos, fue separada la factoría de cajas de cartón. Casi $85 \%$ de sus acciones quedó en manos de Cervecería que le traspasó terrenos, edificios y maquinaria requerida para su funcionamiento. Para su instalación recibió una concesión de 20 años: por ser «industria nueva», conforme a la ley estatal de diciembre de 1927 sobre protección a la industria, pagaría sólo $25 \%$ de los impuestos locales.

En 1929 se constituyó la Compañía Comercial Distribuidora, siguiendo la lógica de los mercados, parecía evidente que la primera plaza que debía cubrirse era la Ciudad de México, principal consumidora era la encargada de la cerveza que se enviaba por tren hacia el centro del país. En 1929 se marca el inicio de su expansión a otros puntos del país al comprar en la ciudad de México la Cervecería Central. Se invirtieron poco más de 207 mil pesos. Había que ampliar la planta y dotarla de la maquinaria y aparatos necesarios. La negociación fusionada mantuvo su nombre original de Cervecería Central.

La Central producía cerveza de barril bajo las marcas Bohemia y Cinta Roja y -tras ser adquirida- vendía cerveza embotella que recibía de Monterrey. En 1931 para abatir costos, se instaló una de las secciones de embotellar de Cuauhtémoc y arrancó en la capital la elaboración de la marca Don Quijote. Ese mismo año, se fusionaron las administraciones de Cervecería Central y de la Compañía Comercial Distribuidora de la Ciudad de México que pasaron a manejarse desde un solo centro operacional. El capital de la Central ascendía a fines de 1935 a un millón y medio de pesos. Durante 1928 Vidriera Monterrey, S.A., firmó un contrato de asistencia técnica con industrias de Bélgica para la construcción y operación de una planta de vidrio plano en Monterrey, Nuevo León, llamada Vidrio Plano, S.T.

\section{Los años treinta: la tendencia a la integración industrial}

Entérminos económicos los empresarios regiomontanos recibieron apoyo del Estado; cabe señalar que a fines de 1927 el gobernador Aarón Sáenz expidió una nueva legislación para fomento de la industria, ampliando los estímulos y garantías ofrecidos en tiempos de Bernardo Reyes gobernador del estado de Nuevo León (1900). En 1927 el gobierno del estado de Nuevo León profundizó una legislación existente desde 1888, la Ley sobre Protección a la Industria (Periódico Oficial del Estado de Nuevo León, 1927) favorable al capital y al específico desarrollo industrial, ley que se anticipó con claridad a las que a escala nacional se sancionarían en los años treinta y cuarenta. Este ordenamiento declara el fomento industrial como de «utilidad pública» usando una expresión que ya había aplicado Bernardo Reyes. A diferencia de los decretos anteriores, las franquicias se otorgaban no sólo a industrias nuevas sino también a aquellas que ampliaban su tamaño, 
capital o número de trabajadores. Se concedían hasta por veinte años, eximiendo el $75 \%$ de los impuestos estatales y municipales.

Una nueva legislación también los favoreció, la Ley sobre Franquicias a la Constitución de Nuevas Sociedades Anónimas (Periódico Oficial, 1934). Esta Ley beneficiaba exclusivamente a las sociedades industriales o las que fomentaran la industria en Nuevo León y eximía del pago del $75 \%$ de los derechos de inscripción en el Registro Público de la Propiedad a los inmuebles en que se montara la fábrica o el organismo de fomento industrial. Gracias a esta legislación la expansión que se manifestó a partir de mediados de los treinta, incluyendo modalidades que se acentuarían en la década de los cuarenta, influenció: 1) la tendencia a la integración industrial; 2) La puesta en marcha de plantas productivas en diferentes lugares del país y en algunos casos en el exterior; es decir, realizó: a) una integración vertical a través de empresas jurídicamente independientes; b) una cobertura del mercado nacional en términos crecientemente oligopólicos; c) instalación de plantas en otros lugares del territorio mexicano. A esta integración industrial se le conoció, como empresas-madre, posteriormente holding (y los grupos que impulsaron) intensificaron su ciclo de adaptación al nuevo régimen político, superando la crisis del 1929 y comenzaron a usufructuar el aparato de protección, subsidios, concesiones, créditos y consumo dirigido que permitía un Estado dedicado a estimular la industrialización de México (Cerutti, 2000).

El caso más conocido y popular fue precisamente Cervecería Cuauhtémoc, que desde 1921 comenzó a transformar sus departamentos internos en empresas autónomas. Estableció un esquema de organización de la compañía y sus filiales, así como el procedimiento para su reestructuración administrativa y legal. La reorganización implicó la separación de varias empresas para constituirse como sociedades independientes, lo que permitió que se administrasen con mayor eficiencia y éxito. Asimismo se creó una compañía tenedora que se convertiría en el centro del recién organizado grupo que tenía como empresa madre a la Cervecería Cuauhtémoc. Lo primero que se hizo fue desagregar las actividades que se agrupaban bajo Fábricas Monterrey, dando lugar en enero de 1936 a Empaques de Cartón Titán, S.A., y Malta, S.A., como se observa en la Tabla IV.

Cervecería Cuauhtémoc aportó los edificios donde estas fábricas se ubicaban, los terrenos, maquinaría y otros activos, recibiendo acciones de cada una en proporción a su aportación. Como parte medular de la reorganización se constituyó en 1936 una empresa controladora de las actividades de las distintas sociedades que ahora formaban el grupo.
TABLA IV. GRUPO CERVECERÍA CUAUAHTÉMOC

\begin{tabular}{|c|c|c|}
\hline \multirow{2}{*}{ Empresas } & Año de & Grupo \\
\hline & Fundación & Actual \\
\hline Compañía Comercial Distribuidora & 1930 & \\
\hline Troqueles y Esmaltes & 1930 & \\
\hline $\begin{array}{l}\text { Compañía Cervecera Veracruzana, } \\
\text { S.A }\end{array}$ & 1933 & FEMSA \\
\hline Cervecería del Oeste, S.A & 1935 & \\
\hline Empaques de Cartón Titán, S.A. & 1936 & \\
\hline Malta, S.A. & 1936 & \\
\hline Valores Industriales S.A. (Holding) & 1936 & VISA \\
\hline $\begin{array}{l}\text { Fomento de Industria y Comercio } \\
\text { (FIC) Subsidiarias: }\end{array}$ & 1936 & \\
\hline • Vidriera México, S.A. & 1934 & Grupo \\
\hline - $\quad$ Cristales, S.A. & 1936 & Vitro \\
\hline - $\quad$ Vidrio Plano, S.A. & 1936 & \\
\hline
\end{tabular}

Fuente: Páginas Web de las empresas

Cervecería Cuauhtémoc dejó de ser la cabeza de todas las operaciones cediendo esta tarea a Valores Industriales S.A., (VISA), que por muchos años da el nombre al grupo empresarial originado a partir de la cerveza y de su explotación. El cambio realizado fue sólo estructural ya que Cervecería Cuauhtémoc adquirió casi la totalidad de las acciones de la sociedad. Nunca antes se había creado un holding, este nuevo tipo de organización daba independencia económica a las diferentes ramas, ya que bajo esta nueva estructura, podrían emitir acciones y bonos por su cuenta, solicitar créditos y obtener mejor financiamiento al contar con el respaldo de VISA. La reestructuración dio mayor autonomía a las nuevas empresas a la vez que permitió a los propietarios controlarlas de manera más efectiva a través de la adquisición de todas o la gran mayoría de las acciones por parte de VISA (Ortega Ridaura, 2003).

En 1930 se crea Troqueles y Esmaltes, S.A., ese mismo año la actividad de la fábrica de malta resultó estimulada con la exención de impuestos estatales y municipales por 17 años. Como la malta era esencial para la elaboración de la cerveza, se realizaron inversiones específicas para asegurar el abasto desde distintos puntos del país. En 1934, a propuesta del general Abelardo Rodríguez, se compró la Fábrica de Malta de Tecate, en Baja California. Otra fábrica de malta propiedad de Cervecería se ubicó en Azcapotzalco, Ciudad de México, surtía a la fábrica de la capital (Cerutti, 2003). En 1936 y debido a sus óptimos resultados y creciente expansión el departamento de fabricación de este insumo fue separado jurídicamente de Cervecería y quedó registrado bajo la denominación: Malta, S.A. (procedimiento que siguieron otros departamentos). 
El 30 de abril de 1936 nacía Malta, S.A., y se refundaba Fábricas Monterrey, S.A. Los mismos comparecientes que habían representado a Cervecería y a Famosa dejaban constancia de los siguiente: a) la antigua Famosa (la de 1929) cambiaba (cedía) su denominación y pasaba a ser Malta, S.A.; b) el capital inicial de esta última ascendía a un millón de pesos; c) su objeto sería la fabricación y explotación comercial de productos industriales diversos, d) la marca comercial Famosa era transferida a Malta, S.A.; e) Cervecería Cuauhtémoc y la antigua Fábricas Monterrey, S.A., que nacía con un capital de 750 mil pesos (ambas era a la vez sus principales accionistas; f) la nueva Famosa se dedicaría específicamente a la fabricación y explotación y venta de tapón corona o corcholata, tapas para frascos y botellas y toda clase de artículos de metal laminado, g) para su instalación se haría cargo de la compra-venta de gas ácido carbónico; $h$ ) le fue cedido un terreno de aproximadamente $7000 \mathrm{~m}^{2}$ (situados entre la actual Fábrica Monterrey y avenida Cuauhtémoc) y además los bienes, cuentas y valores que se consideraron convenientes para un adecuado desempeño. Los dueños de la Cervecería mantuvieron el control de su paquete accionario.

En 1936 se estableció Titán, S.A., como una empresa independiente, con un capital inicial de 750 mil pesos y 180 colaboradores. Se fue expandiendo hasta cubrir toda clase de empaques de cartón. Originalmente Titán era un departamento de empaque que formaba parte de Fábricas Monterrey. Su labor se limitaba a la fabricación de cajas de cartón corrugado. Sus accionistas principales fueron Famosa y la misma Cervecería Cuauhtémoc, sociedades que transfirieron a la nueva diversos bienes (terrenos, maquinaria, productos, edificios, materias primas). La Vidriera Monterrey S. A., refundada en 1934 como Vidriera México, S.A., se establece con el objetivo de satisfacer la creciente demanda de envases de vidrio en el país. La exportación de botellas de vidrio, artículos de cristalería y vidrio plano a Guatemala, El Salvador, Honduras, Nicaragua, Costa Rica y Panamá comienza a partir de 1935. En 1936 se crea Fomento de Industria y Comercio (FIC), ahora Vitro, S. A. de C. V.

Cervecería impulsó y compartió actividades de abastecimiento energético para la producción y distribución de materias primas y la localización de respaldo financiero. En 1930 se convino con la Compañía de Luzy Fuerza Motriz, S.A., le proporcionará la fuerza eléctrica y el vapor necesario a tarifas preferenciales. En 1933 se actualizó este contrato con la Compañía de Tranvías, Luz y Fuerza Motriz de Monterrey. Ese mismo año se construyó una unidad para emergencia, que funcionaba con gasolina, para evitar paralizaciones de la planta en caso de escasez de energía eléctrica.
En los años treinta, ante las dificultades que solía implicar la fusión de plantas en operación, una estrategia exitosa fue la compra directa de la cerveza a productoras independientes que a partir de estos acuerdos, pasaban a maquilar sus marcas más reconocidas para Cuauhtémoc. Fue un procedimiento que facilitó la rápida penetración en mercados muy alejados de la base productiva regiomontana y que sustentó una mayor capacidad de distribución.

En 1933 se constituyó la Compañía Cervecera Veracruzana, S.A., en la Ciudad de México, su objeto era dedicarse a operaciones de compraventa de cerveza, aguas minerales, gas carbónico, cajas refrigeradoras y otros útiles para restaurantes, cantinas y demás establecimientos que expendieran las bebidas mencionadas. Subsidiaria de Cuauhtémoc, estaba destinada a proveer materias primas, incitar las fórmulas y clases de cerveza requeridas y vigilar la cantidad de la producción.

La Compañía Cervecera Veracruzana celebró contratos con Cervecería de Nogales para asegurar la distribución de cerveza y hielo, su compromiso era vender todos los artículos que elaborara la cooperativa, mientras que Nogales se comprometía a producir toda la cerveza que el mercado requiriese, ya en botella o en barril. El acuerdo se firmó por 15 años. Hacia finales de 1933 Cervecería de Nogales empezó con los primeros cocimientos de cerveza y para mediados de 1935 se reconocía ya la gran aceptación del producto envasado en botella en Veracruz, Orizaba, Jalapa y otras poblaciones. Abastecedora de casi todos los estados del sureste, la Veracruzana S.A., manifestó un considerable desarrollo, fue necesario aumentar su capital a 250 mil pesos y a la vez, trasladar su domicilio a Monterrey.

En 1935 la Cervecería Cuauhtémoc compró la Cervecería Occidental en Guadalajara. Se planteó que en Guadalajara se elaborarán algunas de las marcas más baratas de Cuauhtémoc: Monterrey, Indio - Quijote, bajo la responsabilidad de una sociedad que denominarían Cervecería del Oeste, S.A. En los términos de quienes alcanzaron el acuerdo se ahorraba en fletes y se reducía considerablemente el problema de la competencia con las cervezas baratas en aquella región. La Occidental era la única que producía allí mismo cerveza embotellada, mientras que la restante cervecería de la ciudad (La Estrella) se dedicaba exclusivamente a la cerveza de barril.

En el sector financiero en septiembre de 1931, las muy recientes modificaciones a la Ley Monetaria llevaron a estudiar la posibilidad de crear un banco en Monterrey, sustentado por industriales, estaría destinado a impulsar el desarrollo fabril. Sin embargo, debido a las condiciones económicas que presentaba la coyuntura 
depresiva se detuvo el proyecto. Poco tiempo después con el asesoramiento y consejo de Manuel Gómez Morin, se reconsideró y se acordó compartir la creación de la Sociedad de Crédito Industrial de Monterrey, S.A.

En 1932 Cervecería suscribió 5\% (25 mil pesos) del capital social del banco, que ascendió inicialmente a medio millón. En 1934 aportó 50 mil pesos más. A lo largo de su desarrollo Cervecería había mantenido estrechas relaciones con el Banco de Londres y México. Incluso en 1932 convino en darle el manejo de la mayor parte de los negocios y poner en sus manos todas las cobranzas del país. En 1933, en plena depresión, acordó prestarle dinero para que saldara su deuda con el Banco de Montreal (anterior encargado de las cobranzas de Cervecería). Para respaldar este préstamo se hizo una emisión de bonos hipotecarios a favor de Fábricas Monterrey y Cervecería Central, que el mismo banco se encargó de colocar. En 1934, cuando el Banco de Londres necesitó aumentar su capital, recurrió a varias empresas para convertirlas en accionistas, Cervecería suscribió entonces 150 mil pesos.

En 1936 Cervecería adquirió un lote de 1500 acciones en la Compañía General de Aceptaciones, una de las sociedades de crédito más antiguas de Monterrey, fue establecida como parte de la reorganización del grupo Cuauhtémoc para facilitar las transacciones financieras entre sus diversas firmas, permitiendo que las compañías con excedentes transfiriesen sus balances a las compañías con déficits, y para facilitar o garantizar operaciones de crédito de las empresas Cuauhtémoc con otras instituciones financieras o en el mercado.

Posteriormente, Aceptaciones extendió sus actividades a miembros del grupo Vidriera, se destacó hasta los años sesenta por los préstamos que otorgaba para la compra de maquinaria, refacciones y materias primas. Durante los años cincuenta se conocieron varios casos en que apareció Cervecería avalando a esta sociedad en operaciones de importancia (Cerutti, 2003). En 1936 se cambia el nombre de Sociedad Cooperativa de Ahorro e Inversiones para los Empleados y Operarios de la Cervecería Cuahutémoc, S.A., por el de Sociedad Cuauhtémoc y Famosa (SCYF). El 12 de mayo de 1936 fue fundada Valores Industriales S.A., VISA, empresa tenedora de las compañías Cuauhtémoc.

Las acciones empresariales más importantes en este periodo sitúan en 1930 a la Cervecería Cuauhtémoc, que en términos de innovación del producto substituye el tonel de madera para el envasado de la cerveza de barril, por cilindros metálicos. Esto hizo posible la pausterización de este tipo de cerveza, dando al consumidor un producto con más ventajas, además de evitar por completo la fuga de gas carbónico. En esta década se utilizó por primera vez el óvalo de
Carta Blanca como icono de la marca. En 1930 se iniciaron las exportaciones de Cervecería Cuauhtémoc de manera oficial y sistemática.

\section{Los años cuarenta y cincuenta: la sustitución de} importaciones y el desarrollo estabilizador

El crecimiento hacia fuera se extiende desde la independencia hasta la gran depresión de 1933, coyuntura que marca el viraje al modelo de desarrollo hacia adentro. Más aún el viraje del modelo de desarrollo se da entre la depresión y el final de la guerra (Pinto, 1991) .La coyuntura de guerra, la escasez de manufacturas importadas y la ampliación del mercado interno tornaron cada vez más necesario en México, la producción interna de bienes transformados. Entre 1940 y1980 se dio en México un nuevo modelo económico la sustitución de importaciones que se caracterizó por tener su base en el proteccionismo económico y en la significativa participación estatal en un considerable número de ramas de la economía.

En los años cuarenta, México consideró que debía industrializarse para acelerar su paso e ingresar en el conjunto de países llamados «desarrollados». El proceso de industrialización que se inició entonces requería el fortalecimiento de una industria intermedia que llevara, poco a poco, a fabricar en México todo lo que hasta ese momento se tenía que importar en el extranjero. Ese es el comienzo del proceso llamado sustitución de importaciones (Puga Espinosa \& Torres Mejía, 1995). Llegar a ese punto implicó llevar a cabo tareas pendientes de la Revolución Mexicana y convertir al Estado en el pivote del crecimiento económico. La reforma agraria cardenista, la expropiación petrolera, la nacionalización de los ferrocarriles, la creación de Nacional Financiera, del Instituto Politécnico Nacional y de otras instituciones fueron las bases que se necesitaban para dar ese impulso al proceso industrializador.

El modelo proteccionista funcionó satisfactoriamente durante varias décadas, numerosas empresas se fundaron y crecieron a lo largo del periodo. En Monterrey, la industrialización siguió esta pauta durante las décadas de los cincuenta y sesenta. Las empresas del grupo Cuauhtémoc continuaron su expansión y consolidación en esta etapa (Datos históricos tomados de las páginas Web de las empresas). Los antecedentes históricos de las empresas señalan en torno a Vitro que Fabricación de Máquinas, S.A. (FAMA), inicia operaciones en 1943, buscando el desarrollo de tecnología propia en función de la escasez de equipo y repuestos de maquinaria durante la segunda Guerra Mundial; Vidriera los Reyes S.A., se establece en Tlalnepantla, Estado de México en 1944, teniendo como función la fabricación de envases de vidrio; en 1945 Vidriera Guadalajara se incorpora a Vitro para satisfacer la demanda de envases de vidrio en el occidente y centro del país; en 1947 Fomento de Industrias y Comercio, S.A. crea la 
Clínica Vidriera, A.C., para brindar servicio médico a sus trabajadores y familiares; en 1956 Vidrio Plano de México, S.A., inicia operaciones en la ciudad de México, fabricando Vidrio de estiraje vertical en 2 y 3 milímetros de espesor. Fomento de Industrias y Comercio (FIC) y OWENS CORNING FIBERGLASS CO, se asocian y crean VITROFIBRAS, S.A., en 1957; ese mismo año, Vitro adquiere Cristales Mexicanos, S.A. un productor de vajillas y productos de vidrio para el hogar situado en Monterrey.

En la década de los cuarenta, el acelerado crecimiento industrial experimentado en Monterrey y su área metropolitana demostró la incapacidad de las compañías de electricidad para satisfacer la creciente demanda. Por tal motivo, en 1944 varias empresas locales se unieron para montar en copropiedad una planta generadora, destinada a suministrar energía de acuerdo con las necesidades de cada uno de los accionistas. La denominada Planta de Fuerza Eléctrica del Grupo Industrial involucró a Cervecería Cuauhtémoc (aportó $6.45 \%$ del capital), Fábricas Monterrey, Malta, Empaques de Cartón Titán, Vidriera Monterrey, Vidrio Plano, Cristalería, Vidrios y Cristales, Hojalata y Lámina, Troqueles y Esmaltes, Keramos y Cementos Mexicanos. La planta operó inicialmente con una capacidad de $15000 \mathrm{kw}$ y para financiar su construcción se emitieron obligaciones hipotecarias por 8 millones de pesos, conjunta y solidariamente por todas las empresas copropietarias. En 1950 aumentó su capacidad a 29800 kw y en 1953 a 44500 kw.

La Cervecería Cuauhtémoc en 1940 funda Almacenes y Silos, bodegas requeridas para el almacenaje de los productos de Cervecería Cuauhtémoc. Fue constituida sobre la base de 500 mil pesos el 8 de noviembre de 1940 con objeto de almacenar bienes y mercancías pero también para transformar las mercancías con el fin de aumentar su valor. Podía asimismo construir bodegas y dedicarse a la compraventa de mercancías. Empleada sobre todo como responsable de las bodegas requeridas para el almacenaje de diversos productos del grupo, la nueva empresa tuvo como accionista principal a Malta (4650 acciones sobre cinco mil), en tanto que Empaques Titán y Roberto Garza Sada figuraban con 100 acciones cada uno. Tanto Malta como Empaques cedieron parte de sus terrenos y bodegas para el funcionamiento de Almacenes. Para agosto de 1947 se había decidido duplicar el capital inicial.

Como parte de sus innovaciones en 1948 introdujeron el uso de hielo triturado en los puntos de venta para ofrecer al consumidor cerveza fría. En 1953 introducen la botella «transparámbar» para impedir la entrada de luz que pudiera afectar la calidad de la cerveza. En relación al transporte ferroviario, en 1953, ante la necesidad de una nueva compra de vagones de carga -los existentes estaban ya en muy malas condiciones- la Cervecería gestionó un crédito con Nacional Financiera por 10 millones de pesos.

En 1954 adquirieron la planta de Cervecería Cuauhtémoc en Tecate, Baja California Norte. Allí se elaboraba una pequeña marca regional con el nombre de Tecate. Cervecería Cuauhtémoc tomó esta marca y la lanzó a nivel nacional, convirtiéndola en la primera cerveza en lata de México. Las plantas que se articulaban en la Compañía Cervecera de Tecate, S.A. comprendía: la Compañía Manufacturera de Malta, S.A., la Compañía Industrial de Baja California, S.A., y Aceitera de Tecate, S.A. Se sumaba a la participación accionaria en tres empresas filiales: Tecate del Pacífico, S.A., Tecate, S.A. y Fomento Comercial, S.A. Cervecería Cuauhtémoc estimó muy conveniente para el desarrollo de los negocios, la compra de los paquetes accionarios en este grupo de plantas industriales, toda que vez permitiría a la empresa aumentar considerablemente sus negocios, así como atender los mercados de importancia, con la debida oportunidad y gran economía en los gastos de transporte.

Además de hacer posible un incremento importante en la producción de cerveza e insumos, incorporó marcas que estaban debidamente posicionadas en el gusto del consumidor del noroeste mexicano como Tecate. Con la adquisición de esta compañía cervecera se manifestó un sustancial aumento del capital social de Cervecería: 65 millones de pesos. Tal incremento quedó representado con la emisión de 150 mil acciones preferentes y 500 mil ordinarias, las cuales fueron totalmente suscritas con la aportación y respaldo de todos los bienes de las empresas ya mencionadas. El capital de la Compañía alcanzó entonces los 100 millones de pesos. En 1954 fueron incorporadas las unidades industriales de las ya citadas Cervecería Central, S.A., Cervecería del Oeste, S.A., y Cervecería de Nogales, S.A. Las compañías cambiaron sus respectivas denominaciones por Cervecería Cuauhtémoc, Fábrica en el Distrito Federal, Fábrica en Guadalajara y Fábrica en Nogales. En 1958, se dio un aumento de capital por 70 millones de pesos suscrito en gran medida, con la aportación de Cervecería del Humaya S. A., situada en Culiacán, Sinaloa. Traspasó el conjunto de sus bienes, materias primas, productos elaborados, inversiones, créditos y cuentas por cobrar, marcas y patentes, nombres comerciales, derechos y todo su activo, sin limitación alguna. En 1957 se estableció Grafo Regia como una empresa independiente, que anteriormente era un departamento interno de la Cervecería Cuauhtémoc, responsable de proveer etiquetas.

Los empresarios de Monterrey se dieron a la tarea de la procuración de energéticos, de vital importancia es el caso de la puesta en marcha en 1947 de la empresa Gas Industrial de Monterrey, S.A., constituida para tender un segundo gasoducto desde Texas, cuyo objetivo era abastecer la planta fabril de la ciudad. 
La inversión inicial fue de dos millones de pesos. Participaron las siguientes empresas accionistas: Malta, S.A., Fundidora de Fierro y Acero de Monterrey, Fábrica de Ladrillos Industriales y Refractarios, Cementos Mexicanos (Cemex), Cervecería Cuauhtémoc, Vidrio Plano, Vidriera Monterrey, Hojalata y Lámina (HYLSA) Troqueles y Esmaltes, Fabricación de Máquinas, Keramos, Vidrios y Cristales, Cristalería, Fábricas de Monterrey y Empaques de Cartón Titán (Cerutti, 2000) .La participación de Industrias Monterrey S.A., (IMSA) en la rama de productos metálicos se fue ampliando en 1946, fabricación de muebles metálicos, en 1956, la producción de flejes de acero. Industrias Monterrey también incursionó, en esta primera etapa y desde 1945 en la comercialización de automóviles (Cerutti, 2003).

No obstante en México, la industria nacional pese a sus esfuerzos no logró instaurar un crecimiento hacia dentro, la sustitución de importaciones no había sido planeada adecuadamente para operar como un todo en cada una de sus etapas, por consiguiente el modelo entró en crisis. Empezó a surgir una nueva forma de acumulación que buscó cambiar la relación entre el Estado, el capital nacional y el capital extranjero, cuyo eje pasó de ser el comercio exterior a ser la producción de bienes de consumo, el modelo se conoció como el desarrollo estabilizador cuyo pilar fue el crecimiento de la producción estatal (Basáñez, 1991).

\section{Los sesenta: maduración industrial y financiera}

Eldesarrolloestabilizadormantuvoen sus características generales las premisas de la primera década de la industrialización, pero las reforzó a partir del establecimiento de un tipo de cambio estable, de una política muy favorable al capital privado, y de una actitud de apoyo restringido a la inversión extranjera que permitió el establecimiento de numerosas empresas de capital mixto, las cuales al contar con una parte de capital mexicano se beneficiaban de la protección que el gobierno brindaba a las empresas nacionales (Baena Paz, 2005).

El largo proceso de maduración industrial y financiera se expresó en la década de los sesenta, alcanzando Monterrey aportar casi el 10\% del PIB del país. La evolución de las empresas, señala incremento de la producción, innovaciones y adquisiciones. Cervecería Cuauhtémoc en el rango de las innovaciones al producto, en 1960, lanzó al mercado el envase Caguama con capacidad de casi un litro. En 1964 se introduce la modalidad del sistema abresolo en envases de lata, proporcionando una ventaja más al consumidor, que anteriormente requería el uso de un abridor. En 1967 Cervecería Cuauhtémoc introdujo el envase quitapón. La rosca en el cuello de la botella permite el destapado manual sin la necesidad de un abridor. En 1969, se introdujo al mercado el envase abridor para permitir un destape más cómodo de la botella quitapón, utilizando el diseño especial en su parte inferior. En ese mismo año se construyó la planta elaboradora de cerveza más moderna y avanzada de América Latina de su época en Toluca, Estado de México.

Vitro en 1960, ante el descubrimiento de depósitos de sal en García, Nuevo León, fomenta la creación de la Industria del ALCALI, S.A., empresa que introdujo el clásico proceso «solvay» para producir carbonato de sodio. Para 1963, el subgrupo FIC -que integraba a todas las empresas del vidrio- producía el $81 \%$ del consumo total de México. Para ese año, 50 de las siete empresas de las principales exportadoras del vidrio pertenecían al subgrupo FIC. La integración de esta industria se da al alto grado, ya que con excepción del nitrato y del bórax, las materias primas que requiere son de origen nacional (MartínezAssad, 1984). Asociado con una importante compañía cervecera y embotelladora de refrescos en Centroamérica, en 1964 Vitro participó en la constitución de COMEGUA buscando satisfacer el mercado de envases de vidrio en Centroamérica y el Caribe. Se establecieron plantas fabricantes de envases de vidrio en Costa Rica y Guatemala. En 1964 Vitro se asoció a Philadelphia Quartz para crear Silicatos de Sodio y Meta Silicatos (hoy PQ Química) (Pozas, 1994). En 1968 Vidrio Plano de México, S. A. arranca su primera línea de vidrio flotado con el apoyo y asistencia de tecnología de PIKINGTON BROTHERS LIMITED. Este proceso incrementa la producción y la calidad del vidrio dando un paso importante en el desarrollo y futuro de Grupo Vitro.

\section{Los setenta: la formación de los grupos industriales}

Los años 1970-1976 manifestaron con claridad los signos de agotamiento del ciclo de la industrialización protegida y desataron otros problemas, como la espiral inflacionaria, el endeudamiento externo, los conflictos sociales, y la devaluación de 1976. No obstante, entre 1977 y fines de 1981, México encontró una salida, cuando se dedicó a la explotación y exportación de petróleo, superando con rapidez los efectos de la devaluación de 1976. Una enorme inyección de recursos públicos y de créditos extranjeros brindó liquidez al mercado interior.

En México el proceso de industrialización y la política proteccionista del Estado orientada a impulsar la sustitución de importaciones conllevó a la formación de grupos del sector privado nacional. Las grandes empresas de Monterrey formaron grupos industriales hasta llegar a constituir Grandes Corporativos. Entre 1970 y la crisis de 1982 se constituyó en Monterrey en términos formales, un importante número de conglomerados, gracias a los mecanismos organizativos previos que se venían experimentando desde los años treinta y la capacidad financiera y acelerada por lo signos de agotamiento que presentaba el modelo proteccionista o sustitutivo de importaciones. En México, la práctica de inversión diversificada originada 
a fines del siglo XIX, se constituyó en una estrategia empresarial que buscaba compensar las limitaciones sectoriales, regionales y sociales de un mercado interior de lento crecimiento, dejando de lado la integración esencialmente vertical.

El Estado contribuyó a incentivar la reestructuración a través de estímulos fiscales que se formalizaron en la Ley de Sociedades de Fomento promulgada en junio de 1973. Esta Ley concedía subsidios para auspiciar la integración de empresas en grupos denominados unidades de fomento (Cerutti, 2000). Las dos facultades (subsidios fiscales) que otorgaba el decreto eran: a) compensar utilidades de empresas del grupo con pérdidas de otras cumpliendo con el requisito de que las utilidades sobrantes fueran reinvertidas. Si estas utilidades eran reinvertidas en un plazo no mayor de 30 días, entonces quedaban exentas 100\% del pago de los impuestos respectivos; b) comprar acciones de empresas, invertir capital en ellas y venderlas posteriormente por medio de la Bolsa de Valores, quedando exentas totalmente de los impuestos respectivos» (Basave Kunhardt, 1996).

Se alentó así, la creación de las mayores «empresas tenedoras», es decir empresas controladoras (holding) que consolidaron resultados económicos financieros y fiscales. La empresa "holding» tiene diferentes funciones que podríamos resumir en términos generales en tres: 1) permitir el control de las acciones de otra $u$ otras empresas; 2) controlar el aspecto operacional o de coordinación de las actividades empresariales; y 3 ) resolver los problemas de la acción empresarial. Estas funciones pueden ser desarrolladas por la empresa al mismo tiempo o no. Existen diferentes tipos de «holding» según las necesidades de los empresarios, éstas pueden ser «holding» de grupo, personales, mixtas, etcétera (Cordero \& Santín, 1977).

En el proceso de centralización de capital que desplegaron los grandes corporativos, los objetivos fueron distintos, en algunos casos para alcanzar una mejor integración de sus procesos productivos, en otros para aumentar su control oligopólico en sus respectivos mercados lo que llevó a la compra de empresas competidoras de gran tamaño, y en varios más con el objeto de diversificarse y participar en industrias intensivas en trabajo, buscando elevar la tasa de ganancia grupal de aquellas empresas que participan tradicionalmente en industrias intensivas de capital.

\section{Grupo Industrial}

La industria cervecera es una de las más dinámicas dentro de la economía mexicana, tradicionalmente se ha colocado entre las diez más importantes. En 1973 ocupó el cuarto lugar en cuanto al valor de la producción y las ventas; en 1976 el sexto; además mantenía un alto índice de personal ocupado (cuarto lugar) y principalmente de empleados (segundo lugar 1973) (Secretaría de Industria y Comercio, 1973). La producción de cerveza es una actividad muy rentable, el peso del grupo Cuauhtémoc en esta industria es preponderante, puesto que las compañías cerveceras realizaban el $44 \%$ del total de las ventas y ocupaban el $43 \%$ del total de la fuerza de trabajo empleada en esta industria. Otros grupos poderosos que intervenían son el grupo de la Cervecería Modelo y el Grupo Cremi (de la cervecería Moctezuma) quienes también se caracterizaron por su entrelazamiento con el capital bancario. En sus empresas industriales, el grupo Cuauhtémoc estaba prácticamente desligado de otros grupos.

En 1974 se separan las empresas del grupo industrial y VISA surge como tenedora de Banca Serfín, Cervecería Cuauhtémoc y de las empresas que forman su integración vertical (básicamente empaques: Titán, Famosa, Grafo Regia). La otra tenedora que se forma ese año es Grupo Alfa. Del Grupo Cervecería Cuauhtémoc se separaron 12 empresas que pasaron a constituir el Grupo Industrial ALFA.

VISA, acrónimo de Valores Industriales, S.A., se reitera es una compañía mexicana con sede en Monterrey, constituida el 30 de mayo de 1936, siendo la primer Sociedad Controladora (Holding) bajo el proyecto jurídico formulado por Don Manuel Gomez Morín. La empresa adquiere renombre después del fallecimiento de Don Eugenio Garza Sada una vez que las empresas del grupo industrial se separan en 1974. Las acciones de VISAcotizaron por primera vez en la Bolsa Mexicana de Valores el 19 de septiembre de 1978. Afinales de los años setenta e inicios de los ochenta, VISA diversificó sus operaciones mediante adquisiciones y extiende sus operaciones a agua mineral y refrescos, además de iniciar las operaciones de las tiendas OXXO y realiza inversiones en la industria hotelera, de la construcción, de autopartes, alimenticia y pesquera, éstas últimas posteriormente fueron desincorporadas.

En términos de innovaciones, Cervecería inicia en 1971 el uso de la caja de plástico que aumentaba la protección durante la transportación de las botellas gracias a su diseño ligero y seguro. Además inició en 1977 la producción y uso de la lata de dos piezas, lo que evitaba toda posibilidad de fuga de cerveza y le dio mayor calidad al producto. En 1978 se abre la primera tienda OXXO y en 1979 adquiere su primera franquicia de Coca-Cola.. Cervecería Cuauhtémoc lanzó al mercado en 1979 la primera cerveza mexicana con el nombre de Brisa, adelantándose a su época. Sin embargo esta marca no prosperó y se retiró del mercado varios años después. En 1980 introducen el sistema «Beer Drive» para mejorar la distribución de la cerveza de barril a los centros de consumo, utilizando 
TABLA V. GRUPO INDUSTRIAL CERVECERÍA CUAUHTÉMOC

\begin{tabular}{|c|c|c|c|}
\hline $\begin{array}{l}\text { Empresas } \\
\text { diversas }\end{array}$ & Servicios & Industriales: cerveza/refrescos & $\begin{array}{l}\text { Bancos, financieras } \\
Y \text { aseguradoras }\end{array}$ \\
\hline Grafo Regia, S.A. & $\begin{array}{l}\text { Bodegas de } \\
\text { Depósito, S.A. }\end{array}$ & $\begin{array}{l}\text { Cervecería Cuauhtémoc, S.A., } \\
\text { Monterrey, N. L. }\end{array}$ & Banco de Londres y México, S.A. \\
\hline $\begin{array}{l}\text { Consorcio Minero de } \\
\text { Peña Colorada, S.A. }\end{array}$ & $\begin{array}{l}\text { Almacenes y } \\
\text { Silos, S.A. }\end{array}$ & $\begin{array}{l}\text { Cervecería Cuauhtémoc, S.A., } \\
\text { México, D.F. }\end{array}$ & Banco Veracruzano, S.A. \\
\hline $\begin{array}{l}\text { Empaques y Envases } \\
\text { Flexibles, S.A. }\end{array}$ & $\begin{array}{l}\text { Servicios } \\
\text { Industriales y } \\
\text { Comerciales, } \\
\text { S.A. }\end{array}$ & $\begin{array}{l}\text { Cervecería Cuauhtémoc, S.A., } \\
\text { Guadalajara, Jal. }\end{array}$ & Banco de Juárez, S. A. \\
\hline $\begin{array}{l}\text { Troquelesy } \\
\text { Esmaltes, S.A. } \\
\text { Fábricas Monterrey, } \\
\text { S.A. }\end{array}$ & $\begin{array}{l}\text { Técnica } \\
\text { Industrial, S.A. } \\
\text { Previsión } \\
\text { Social Grupo } \\
\text { Monterrey }\end{array}$ & $\begin{array}{l}\text { Cervecería Cuauhtémoc, S.A., } \\
\text { Tecate, B.C. } \\
\text { Cervecería Cuauhtémoc, S.A., } \\
\text { Nogales, Veracruz. }\end{array}$ & $\begin{array}{l}\text { Banco de Jalisco, S.A. } \\
\text { Cía. General de Aceptaciones, } \\
\text { S.A. }\end{array}$ \\
\hline Azulejos Orión, S.A. & & $\begin{array}{l}\text { Cervecería Cuauhtémoc, S.A., } \\
\text { Culiacán, Sinaloa }\end{array}$ & Banco Azteca, S.A. \\
\hline $\begin{array}{l}\text { Pregoneros del } \\
\text { Norte, S.A. }\end{array}$ & & $\begin{array}{l}\text { Cervecería Cuauhtémoc, S.A., } \\
\text { Toluca, México }\end{array}$ & Banco Hipotecario Azteca, S.A. \\
\hline $\begin{array}{l}\text { Fábricas Orión, S.A. } \\
\text { Peerles-Tisa, S.A. }\end{array}$ & & $\begin{array}{l}\text { Malta, S. A., Monterrey, N.L. } \\
\text { Malta, S.A., México, D.F. }\end{array}$ & Financiera de Tampico, S.A. \\
\hline & & & Hipotecaria Serfín, S.A. \\
\hline $\begin{array}{l}\text { Fabricación de } \\
\text { Máquinas, S.A. }\end{array}$ & & Malta, S.A., Tecate, B.C. & $\begin{array}{l}\text { Monterrey Compañía de } \\
\text { Seguros, S.A. }\end{array}$ \\
\hline $\begin{array}{l}\text { Planta Eléctrica } \\
\text { Grupo Industrial }\end{array}$ & & Coca Cola & Finanzas Monterrey, S.A. \\
\hline $\begin{array}{l}\text { Talleres Industriales, } \\
\text { S.A. }\end{array}$ & & $\begin{array}{l}\text { Construcciones } \\
\text { e Inmobiliarias }\end{array}$ & Inversiones y Holdings \\
\hline Tapón Corona, S.A. & & Fraccionadora Las Flores, S.A. & Sociedad de Fomento Industrial \\
\hline
\end{tabular}

Fuente: elaborado a partir de la información que presenta Salvador Cordero y Rafael Santín en su obra de Los Grupos Industriales: una nueva organización económica en México, El Colegio de México, 1977, donde analiza cincuenta grupos industriales de control privado nacional e información de la página Web de la empresa.

camiones pipa y tanque enfriadores (FEMSA, 2009).

\section{El Grupo Monterrey}

Los grupos industriales Cervecería Cuauhtémoc, Alfa, Vidriera y Cydsa constituyen lo que generalmente se les denominó como el Grupo Monterrey (en la actualidad no existen como grupo). El criterio para su delimitación de cada subgrupo es la interrelación de sus empresas por medio de una que controla las acciones-empresas holding-y para englobar estos subgrupos con el grupo Monterrey, el criterio central es que aquéllos se han formado a través de la transferencia de una parte de los intereses de un subgrupo hacia la estructuración de otro. El Grupo Monterrey se distinguió por su alto grado de dinamismo en cuanto al empleo de tecnología y al tipo de integración industrial; políticamente, por sus argumentos nacionalistas, industrialistas y autoritarios (Labastida, 1986). A este conglomerado también se le denominó Grupo Visa, por ser ésta la empresa que controla las acciones, en los setentas se integró por unas 45 empresas.

No obstante, que las empresas creadas por el Grupo Monterrey en distintos momentos del siglo, tuvieron su verdadero despunte modernizador e innovador de 132 proyectos económicos en los años cuarenta, cuando se inicia la segunda etapa del desarrollo de la siderurgia y su presencia se hace indiscutible en toda la nación; es en esta etapa cuando observamos una mayor consolidación y expansión de sus grupos. Como un solo grupo, Carlos Martínez Assad (Martínez Assad, 1984) entre otros puntos, observa lo siguiente:

- El momento de aparición de cada una de las empresas que conforman el Grupo Monterrey respondió siempre a las tendencias generales del capitalismo y a las especificaciones de la economía nacional.

- El entendimiento y la relación económica de los distintos subgrupos que lo conforman están vinculados a la pertenencia a un mismo tronco familiar. La comunidad de intereses económicos basada en su similar situación material dentro de las diversas industrias que ocupa cada grupo es lo que da unidad y razón de existir al Grupo Monterrey.

- El conjunto de empresas que forma el Grupo Monterrey tiene un alto desarrollo económico, emplea

HITOS DE CIENCIAS ECONÓMICO ADMINISTRATIVAS 
tecnología moderna, sistemas de producción muy perfeccionados y por sus dimensiones cuantitativas aglutina empresas vinculadas al período capitalista de gran industria.

- En sus empresas predomina el capital nacional, razón que coadyuva a su mantenimiento y las singulariza de las empresas de otros grupos similares del sector de gran industria. Entre 1974 y 1980, el Grupo Monterrey creció desmesuradamente sus conglomerados del tipo de Alfa y Visa se clasificaron entre los primeros de México y América Latina (Alba Vega, 1990).

Es muy importante señalar que el llamado Grupo Monterrey, a la muerte de su fundador Eugenio Garza Sada se dividió en dos: el conjunto de empresas, alrededor de la Cervecería Cuauhtémoc que junto con Banca Serfín constituirían el Grupo Visa comandado por Eugenio Garza Lagüera y el conjunto de empresas alrededor de la siderúrgica Hojalata y Lámina (HYLSA) y de las empresas Nylon de México y Fibras Químicas, quedando al frente Bernardo Garza Sada. Este último se convertiría en el Grupo Industrial Alfa una vez que el gobierno federal en 1973 emitió un decreto para estimular fiscalmente la formación de holdings que bajo el régimen de Sociedades de Fomento Industrial contribuyeran, según criterios cuantitativos preestablecidos, a la creación de nuevos empleos, a incrementar exportaciones, sustituir importaciones, crear nuevas empresas, mexicanizar empresas de capital extranjero, invertir en zonas de menor desarrollo económico, entre otros requisitos. A este decreto se apegaron otros grupos, como el propio Visa, por ello ya no son el Grupo Monterrey, más bien son parte de la Fracción Monterrey.

En el Grupo Monterrey existieron dos grupos financieros: el grupo Serfín (1972) y el grupo Banpaís (1974). El primero se encuentra directamente vinculado al conglomerado Cuauhtémoc y el segundo al grupo del Vidrio. Los dos grupos practicaron toda clase de operaciones: depósitos y ahorro, financiera, de crédito hipotecario, fiduciarias y sumaron aseguradoras y almacenes de depósito. Es importante destacar en este ámbito de operaciones las ligas del grupo Monterrey con otros grupos financieros importantes del país: Eugenio Garza Laguera, Presidente del grupo Cuauhtémoc figuró en los consejos de administración de los grupos Bancomer y Comermex; Bernardo Garza Sada, dirigente del grupo Alfa, estaba en el consejo de administración de la financiera Bancomer (1976-1977).

A nivel de financiamiento y provisión de créditos del exterior, el grupo Monterrey dependió de manera preponderante del capital norteamericano. Como ejemplos pueden mencionarse los créditos de Eximbak (Banco de Exportaciones e Importaciones) a Hylsa que en 1972 cubrieron el 30\% de los costos de obras de expansión. En 1975, la Industria Minera de México (empresa en la que el grupo Alfa participa) recibió un crédito por un consorcio de nueve bancos norteamericanos, éste es el mayor que se ha otorgado a una empresa privada del país. El grupo mantuvo además ligas con intereses financieros norteamericanos mediante el grupo Serfín, vinculado a los grupos Morgan y Chase Rockfeller. En 1975, los principales grupos bancarios mexicanos crearon empresas con participación norteamericana sobre la base de un nuevo concepto denominado «banca múltiple»; el Grupo Serfín adquirió Interamericana de Arrendamientos (CompañíaArrendadora Financiera)en sociedad con el Wells Fargo Bank (Labastida, 1986).

Finalmente, es importante aclarar en cuanto a la consideración de análisis particular del grupo Monterrey que se hace con el propósito de sentar un precedente para observar la dinámica de los diferentes grupos que han partido de un tronco común, el grado de unidad o diferencias a través del tiempo es observado en las particularidades que cada uno reviste. Pero estas características no pueden ser utilizadas en forma generalizada para otros grandes corporativos o grupos de la Fracción Monterrey.

\section{CONCLUSIONES}

- En el México del siglo XVIII ya había una serie de grandes empresas excepcionales que en términos de capital, número de obreros y complejidad de organización de la producción, transporte y comercialización eran realmente importantes, aunque nos comparables con las grandes empresas modernas. Desde 1880 comenzaron a establecerse las primeras grandes empresas modernas en México: esencialmente ferrocarriles, bancos y empresas mineras, aunque también comenzaron a aparecer grandes empresas industriales a fines de siglo, gracias a la disponibilidad de capitales nacionales y especialmente extranjeros.

- El fuerte sello de rasgos regionales y familiares que tuvieron los grupos económicos surgidos desde el siglo XIX hasta las postrimerías de la Revolución de 1910 puede atribuirse a diversos factores: el aislamiento de ciertas áreas, la distancia de las estructuras de poder, las desigualdades en el proceso de integración de algunas zonas geográficas. En la evolución del capitalismo tardío, es en el porfiriato donde encontramos los rudimentos de la industrialización del país, las empresas industriales que le dieron dinamismo nacieron monopólicas.

- Es válido afirmar que los empresarios participan en forma notable en la conformación de ciertas regiones como Monterrey, pero también que la región dio origen al surgimiento y consolidación de hombres de negocios con determinadas características: la clase dominante regional mediante el control de los recursos económicos, de la administración local 
y de la identidad regional, buscó expandir su base material y promover sus propios intereses haciendo compatibles algunas de las principales instituciones de la región: familia, política, empresa económica. A pesar que las regiones son dinámicas y cambian con el tiempo, en Monterrey estas características han perdurado.

- Una amplia porción del norte desempeñó un papel fundamental en la formación e integración del mercado nacional: a) porque el norte comenzó a especializarse en producciones para el mercado interior antes de la llegada del ferrocarril; b) por haber concentrado una vasta proporción del tendido de los ferrocarriles, que lo unían a los grandes sistemas de Texas y el resto del territorio estadounidense, c) por el efecto productivo que ocasionaron las demandas de minerales y metales de la segunda revolución industrial.

- El ámbito de los grupos que surgieron en la época pre-revolucionaria siguió siendo predominantemente regional hasta la década de los años cuarenta, cuando la integración del mercado nacional avanzó de manera considerable con el desarrollo del sistema de comunicaciones y finanzas. Entre 1940 y 1970 las grandes empresas de capital nacional y el conjunto de trasnacionales que se instalaron en México orientaron su producción al mercado interno aprovechando el modelo protegido de sustitución de importaciones.

- En relación al desarrollo de las empresas, observamos que hasta la década de los años cincuenta, los mecanismos más importantes de crecimiento fueron la expansión de las plantas y el establecimiento de nuevas instalaciones. De los sesenta en adelante, se hicieron más comunes las adquisiciones y las fusiones. El crecimiento por medio de las asociaciones, las adquisiciones y fusiones, llevó a un control oligopólico del mercado interno. Las corporaciones reunidas alrededor del Grupo Monterrey, se expandieron y diversificaron: en ciertos momentos se ramificó, ya sea para compensar fallas de mercado y escasez de la demanda, para contrarrestar los ciclos económicos sectoriales, para desplazarse hacia sectores más redituables y dinámicos.

- Entre 1960 y 1980 los vínculos con el capital extranjero adquirieron una mayor importancia para la expansión y la modernización tecnológica de los grandes grupos mexicanos. Los vínculos con el capital extranjero ocasionaron reajustes en la Fracción Monterrey y cambios en las estrategias de las corporaciones. Acentuado por el modelo protegido, crecieron desmedidamente los niveles de concentración del capital en todos los sectores de la economía nacional, fundando un conjunto de grandes empresas privadas en los sectores más dinámicos de la economía. La centralización del capital se detecta de 1974 a 1982, una centralización diferenciada, una industrial (1974-1979) que se trató de una estrategia de integración vertical y horizontal; y una bancaria (1974-1982) que produjo un proceso de reposicionamiento de capitales.

- La consolidación de la fracción Monterrey en el marco protegido del modelo de sustitución de importaciones se explica en el periodo comprendido entre 1940 e inicios de los años setenta, debido al proceso de expansión de los mercados mexicanos, a la política proteccionista gubernamental, a la coincidencia con el impresionante crecimiento de la economía estadounidense de posguerra y a la estabilidad política impuesta por el Estado, una larga etapa que ofreció promisorias ventajas de inversión a los mayores capitales privados, tanto nacionales como extranjeros. Por estos factores es el periodo de fundación y crecimiento de grandes empresas y grupos empresariales, que se consolidaron como oligopolios que dominarían la estructura económica de México en adelante.

- Finalmente, cabe señalar que es en entre 1970 y la crisis de 1982 que se constituyó en Monterrey, en términos formales, un importante número de conglomerados o corporativos. En su enorme mayoría, sus raíces se remontaban a las empresas pioneras de principios de siglo o empresa-madre que aparecieron entre 1930 y 1950. Los mecanismos organizativos previos-que se venían experimentado desde los años treinta- y una densa capacidad financiera favorecieron este fenómeno, aclarado además por los signos de agotamiento que presentaba el modelo proteccionista o sustitutivo de importaciones. 


\section{REFERENCIAS}

Alba Vega, C. (abril-junio de 1990). Las regiones industriales y los empresarios de México. Revista Mexicana de Sociología, 52(2), 29.

Baena Paz, G. (2005). En Estructura socioeconómica de México (pág. 18). México: Publicaciones Cultural.

Barragán, J. I., \& Cerutti, M. (1993). Juan F. Brittinghan y la industria en México, 1859-1940. Urbis Internacional, S.A. de C.V, 160.

Basáñez, M. (1991). En La lucha por la hegemonía en México 1968-1990 (págs. 169-170). México: Ed. Siglo XXI.

Basave Kunhardt, J. (1996). Los Grupos de capital financiero en México, 1974-1995. México: Ed. El Caballito.

Basave Kunhardt, J. (2001). Un siglo de grupos empresariales en México. México: Ed. Porrúa.

Cerutti, M. (enero-marzo de 1983). Burguesía, capitales e industria en el norte de México, Monterrey y su ámbito regional (1850-1910). Revista Mexicana de Sociología, XLV (1), 136.

Cerutti, M. (2000). Propietarios, empresarios y empresa en el norte de México. México: Siglo XXI.

Cerutti, M. (2003). Del Mercado protegido al mercado global, Monterrey 1925-2000. México: Ed. Trillas.

Cerutti, M. (2003). Del Mercado protegido al mercado global, Monterrey 1925-2000. México: Ed. Trillas.

Cerutti, M., Ortega, I., \& Palacios, L. (2000). Empresarios y empresas en el norte de México Monterrey: del Estado oligárquico a la globalización. México: European Review of LAtin American and Caribbean Studies 69.

Collado H., M. d. (enero-abril de 2004). Los empresarios y la politización de la economía entre 1876 y 1930: un recuento historiográfico. Revista Secuencia(46), 51.

Cordera, R. C., \& Ruíz A., C. (1980). Esquema de periodización del desarrollo capitalista en México. Revista Estudios Políticos, V (20-21 ), 78.

Cordero, S., \& Santín, R. (1977). En Los grupos industriales: una nueva organización económica en México (pág. 19). México: El Colegio de México.

Dávalos, J. (1930). Empleados y obreros de la Cervecería Cuauhtémoc. Cuarenta Años, 11.

FEMSA. (2009). FEMSA. Obtenido de http://www. femsa.com/es/

Hernández Laos, E. (1985). La productividad y el desarrollo industrial en México. México: FCE.

INEGI. (1900). Anuario Estadístico de la República Mexicana.

Labastida, J. (1986). Grupos Económicos y Organizaciones Empresariales en México. México: Alianza Editorial Mexicana-UNAM.

Martínez Assad, C. (abril-junio de 1984). Auge y decadencia del grupo Monterrey . Revista Mexicana de Sociología, XLVI(2), 24-25.

Mauro, F. (1972). Los beneficiarios del Desarrollo Regional . En El desarrollo industrial de Monterrey
(1890-1960) (pág. 109). México: SEP/Setentas 52. Ortega Ridaura, I. (2003). Crecimiento, crisis y reorganización laboral Cervecería Cuauhtémoc . 4to. Congreso Nacional de Estudios del Trabajo. México: Centro de las Artes, Universidad de Sonora.

Periódico Oficial del Estado de Nuevo León (3 de Diciembre de 1927).

Periódico Oficial. (16 de mayo de 1934).

Pinto, A. (1991). En América Latina: una visión estructuralista (págs. 242-243). México: UNAM.

Pozas, M. d. (1994). En Modernización de la industria y relaciones de trabajo (pág. 180). México: El Colegio de la Frontera Norte.

Puga Espinosa, C., \& Torres Mejía, D. (1995). México: la modernización contradictoria. México: Ed. Alambra Mexicana.

Romero Ibarra, M. E. (enero-marzo de 2003). La historia empresarialen . Revista Historia Mexicana, LII (3 ), 812-813.

Rosenzweig, F. (1965). La industria. Historia moderna de México, 7, 361.

Secretaría de Fomento Colonización e Industria. (1900). Anuario Estadístico de la República Mexicana. México.

Secretaría de Industria y Comercio. (1973). Estadística Industrial Anual. México: Dirección General de Estadística. 

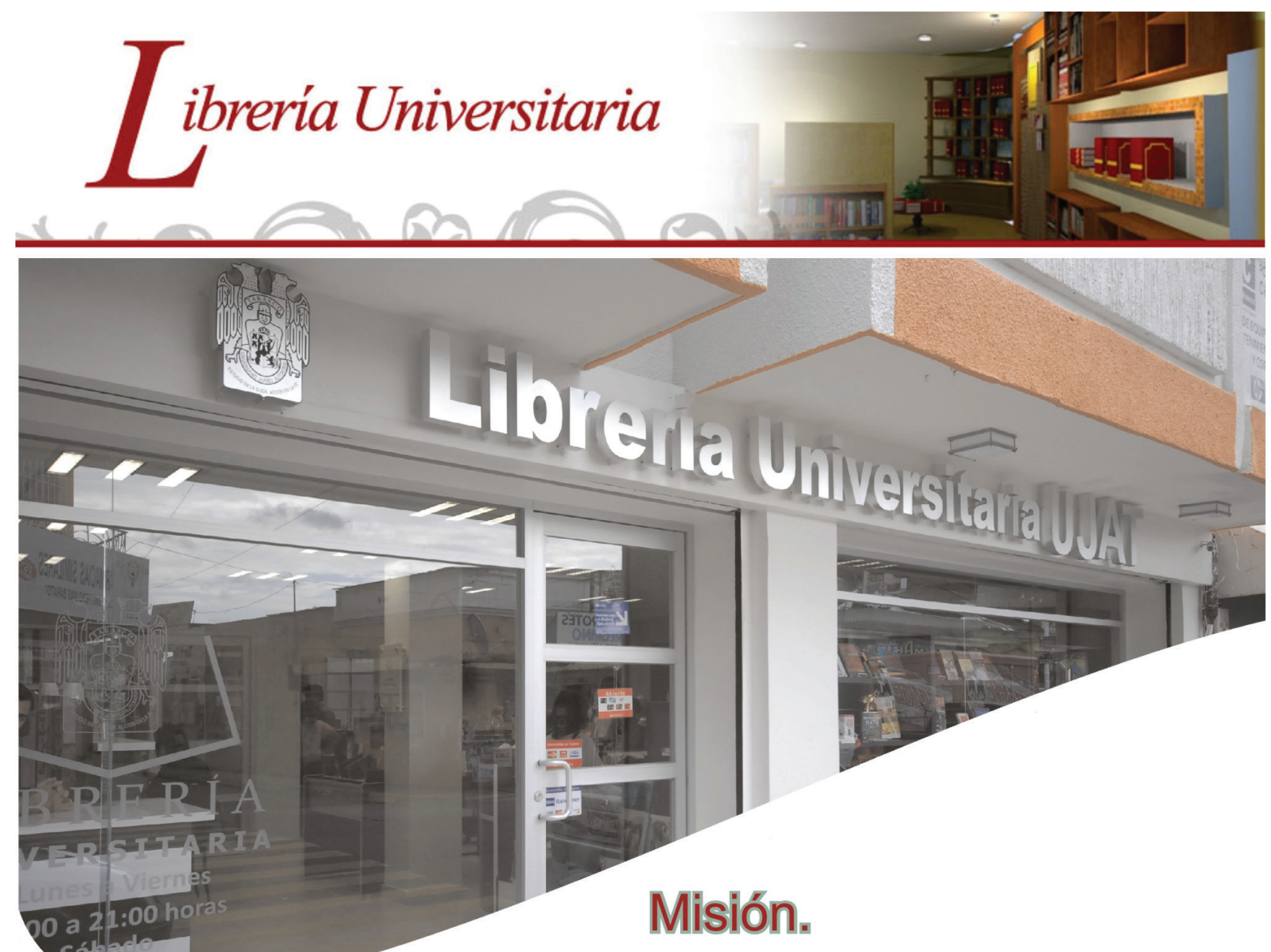

Difundir el fondo editorial UJAT, y los servicios inherentes con el afán de incidir en la formación integral del estudiante y de la

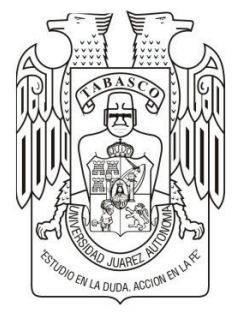
comunidad, mediante la atención, eficiencia, amabilidad y cortesía en el servicio, ofreciendo publicaciones de calidad, con precios accesibles para satisfacer las necesidades de los clientes, contribuyendo así a la proyección nacional de nuestro quehacer tecnológico-cultural como aporte al desarrollo de la sociedad y la cultura latinoamericana.

\section{Visión al 2012.}

Av. 27 de Febrero 626, Col. Centro, C.P. 86000

Villahermosa, Tabasco. Tel: 01 (993) 3124657

Lunes a Viernes de 09:00 a 21:00

Sábados de 09:00 a 13:00

www.ujat.mx

librería@ujat.mx
Ser la mejor librería en la categoría de universitaria en el estado, como centro difusor de la producción editorial universitaria y de otros fondos conformando un espacio cultural incluyente, destacando nuestros valores para vivir en una sociedad en armonía, paz y progreso, manteniendo el nivel de actualidad que exija el momento y con presencia a nivel nacional e internacional.
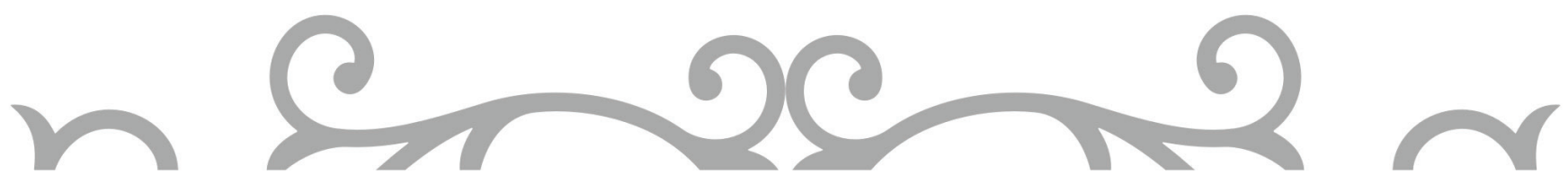